\title{
Metric Drop
}

National Cancer Institute

\section{Source}

National Cancer Institute. Metric Drop. NCI Thesaurus. Code C48491.

A unit of volume used in pharmacy and equal to 0.05 milliliter ( $20 \mathrm{drops} / \mathrm{ml})$. 